\title{
Prognostic Factors, Incidence and Management for Acute Variceal Bleeding in the Liver Transplantation Era ${ }^{*}$
}

\author{
Élio Rodrigues da Silva ${ }^{1}$, Ilka de Fátima Santana Ferreira Boin ${ }^{2}$, Eurípedes Soares Filho ${ }^{3}$, \\ Patrícia Alexsandra Nunes Barros Rodrgiues ${ }^{3}$, Benedito Borges da Silva ${ }^{3}$ \\ ${ }^{1}$ General Surgeon Collaborator of Department of Surgery, Federal University of Piauí \\ ${ }^{2}$ Department of Surgery-Clinical Coordinator of Unit of Liver Transplant-Faculty of Medical \\ Sciences at the State University of Campinas-UNICAMP/SP, Brazil \\ ${ }^{3}$ Federal University of Piauí \\ E-mail: ilkaboin@yahoo.com \\ Received February 5, 2011; revised April 6, 2011; accepted May 19, 2011.
}

\begin{abstract}
Background: Gastroesophageal varices are the most common and clinically important part of the portosystemic collaterals due to their tendency to rupture and cause massive gastrointestinal bleeding. Objective: The aim of this work was to evaluate retrospectively the incidence and the factors of prediction for the treatment of bleeding by gastroesophageal varices in the patients attended in the Emergency Room of the Hospital State University of Campinas (Brazil) from the last ten years. Methods: The method used here consisted of a descriptive and retrospective study carried out from the analyses of the medical records of 769 patients with upper gastrointestinal bleeding of which 220 were admitted because of upper gastrointestinal bleeding caused by gastroesophageal varices during this same period. Results: The results showed that the gastroesophageal varices appeared in $28.6 \%$ of the patients and they were the second most common cause of upper gastrointestinal bleeding. While evaluating factors such as age, sex and the common individual records, it was proved that this disease occurs mainly among people between the third and the fifth decade of life, with the great majority of cases occurring in the fourth decade (29.2\%), of which $76.8 \%$ were male. There was an association of hematemesis and melena in the admission of $57.7 \%$ of the patients and even ascites was a common diagnosis in $48.2 \%$ of them. Most of these patients (40\%) were classified as Child class B at admission. The early endoscopic exam was used for $96.8 \%$ of them and showed the presence of $\mathrm{F} 3$ varices in $38.5 \%$, CB varices in $25.1 \%$ and RCS varices in $12.6 \%$. Most of these varices $(41.5 \%)$ were situated in the distal third of the esophagus. The most used pharmacological treatment was based on octreotide in $45.9 \%$ of the patients. They received $0.05 \mathrm{mg}$ of intravenous octreotide and a maintenance dose of $1 \mathrm{mg}$ per day in $98.6 \%$ of the cases, with efficacy in $74.2 \%$ of the patients. The tamponade with Sengstaken-Blakemore tube was applied in $30.5 \%$ of the patients, but it was observed that $69.7 \%$ of them did not present any considerable progress and this situation led to their death. The endoscopic treatment was performed in $41.8 \%$ of the patients with efficacy in $81.5 \%$ of them. The sclerotherapy was used for $60.9 \%$ of the studied cases with Ethamolin ${ }^{\circledR}$ being the most used for sclerosing. Emergency surgery was used in just $8.6 \%$ of the patients studied and it controlled the bleeding in $78.9 \%$ of the cases. Conclusions: We concluded that gastroesophageal bleeding was an important cause of upper gastrointestinal hemorrhage, even in the liver transplantation era. Factors of prediction for this bleeding were the endoscopic classification, the presence of ascites and the degree of liver failure, according to the Child-Pugh classification.
\end{abstract}

Keywords: Liver Transplantation, Portal Vein Thrombosis, Surgical Technique

\footnotetext{
"Master Thesis from the Postgraduate Course in Medical Science in Surgical General at the "Mestrado Interinstitucional UNICAMP/UFPIFaculty of Medical Sciences at the State University of CampinasUNICAMP/SP, Brazil.
}

\section{Introduction}

Bleeding from gastroesophageal varices is still an im- 
portant cause of hospital internment all over the world and is also one of the most severe consequences of portal hypertension [1-14]. This specific type of bleeding is an immediate threat to life. The mortality of each bleeding episode varies from $20 \%$ to $30 \%$, even increasing from $70 \%$ to $90 \%$ among patients that are seriously sick $[1,7$, 11,12,20-32]. However, the cause of rupture of these varices is not totally clear. Many technological advances have taken place in the diagnosis and treatment of portal hypertension. However, it still causes serious complications such as upper gastrointestinal bleeding (caused by gastroesophageal varices) and spontaneous bacterial peritonitis (caused by ascites).

The purpose of this work was to analyze retrospectively the incidence, the factors of prediction, and results after treatment of bleeding caused by gastroesophageal varices.

\section{Patients and Methods}

This research included only those patients who came from the Emergency Room of the Hospital das ClínicasState University of Campinas (UNICAMP)-SP/Brazil with a diagnosis of upper gastrointestinal bleeding caused by gastroesophageal varices. This retrospective study used information collected from 769 patient medical records of the Emergency Room of the Hospital das Clínicas-State University of Campinas-SP/Brazil from the last ten years.

The data used were: age, gender, type of bleeding, ascites or hepatic encephalopathy presence, portal hypertension etiology, Child-Pugh classification, treatment type and success and evolution during acute phase and one-year after.

The degree of upper gastrointestinal bleeding was classified as mild (little bleeding, without hemodynamics repercussion); moderate (mild clinical manifestation, such as fainting, sweating, cutaneous paleness and stable hemodynamics); and severe (intensive hemodynamics repercussion, such as hemorrhagic shock).

Diagnosis of upper gastrointestinal bleeding and classification of varices were carried out according to the procedure and protocol defined by the endoscopic team at the institution.

Qualitative variables were evaluated with the Chi-square test and Fisher's exact test. Continuous variables were evaluated with the Mann-Whitney and Kruskal-Wallis tests. Categorical variables were evaluated with the Stuart-Maxwell test. Survival analyses employed the Kaplan-Meier method with Log-Rank or Breslow tests. Statistical significance was designated at $\mathrm{P}<0.05$.

\section{Results}

Gastroesophageal varices were the second most frequent cause of upper gastrointestinal bleeding in our service representing $220(28.6 \%)$ of the analyzed cases. It was surpassed only by peptic ulcer disease (Table 1). One hundred and sixty-nine patients $(76.8 \%)$ were male. The age of most patients was between the third and the fifth decade of life, with a peak in the fourth decade $(29.2 \%$ of the cases).

One hundred and twenty patients $(57.7 \%)$ were admitted with a diagnosis of hematemesis associated with melena, with variceal bleeding at a moderate level in $47.3 \%$ of the cases and severe in $14.5 \%$. Thirty-one $(14.6 \%)$ of them died after admission. Among the symptoms and clinical signs identified in those patients, ascites was present in 106 (48.2\%) and liver encephalopathy in $40(18.2 \%)$. Most of them were classified as Child class $\mathrm{B}$ at admission (40\%). Alcohol was identified as the main cause of portal hypertension in $32.3 \%$ of the cases, followed by schistosomiasis $(19.1 \%)$ and viral hepatitis $\mathrm{C}$ in 10\% (Table 2).

Upper gastrointestinal endoscopy was carried out in $213(96.8 \%)$ patients in the first 24 hours after admission. It showed, according to Osaka's classification (1979), F3 (38.5\%), CB (25.1\%), RCS (12.6\%) and LM (41.5\%) varices.

Most of these patients (45.9\%) were submitted to a treatment with octreotide, with good response in $74.2 \%$ of the cases. Sengstaken-Blakemore tube was used in $30.5 \%$ of the patients admitted with a diagnosis of upper gastrointestinal bleeding due to gastroesophageal varices, controlling the bleeding in $49.3 \%$ of the cases, Endoscopic therapy was used in $41.8 \%$ of the patients. Elastic

Table 1. Frequency of the causes of upper gastrointestinal bleeding in the Emergency Room of the Hospital de Clinicas-UNICAMP (Brazil).

\begin{tabular}{lc}
\hline Causes Of Upper Gastrointestinal Bleeding & Frequency (\%) \\
\hline Peptic Ulcer Disease & $264(34.3 \%)$ \\
Esophageal Varices & $220(28.6 \%)$ \\
Acute Gastroduodenal Mucosal Lesions & $209(27.2 \%)$ \\
Gastric Neoplasms & $27(3.5 \%)$ \\
Esophagitis & $23(3.0 \%)$ \\
Mallory-Weiss & $13(1.7 \%)$ \\
Esophageal Neoplasms & $10(1.3 \%)$ \\
Esophageal Ulcers & $03(0.4 \%)$ \\
Total & 769 \\
\hline
\end{tabular}


Table 2. Frequency of portal hypertension causes identified in the patients admitted to the bleeding caused by gastroesophageal varices in the Emergency Room of the Clinical Hospital-UNICAMP (Brazil).

\begin{tabular}{lc}
\hline \multicolumn{1}{c}{ Portal Hypertension Causes } & Frequency \\
\hline Alcohol & $71(32.3 \%)$ \\
Schistosomiasis & $42(19.1 \%)$ \\
Viral Hepatitis C & $22(10.0 \%)$ \\
Viral Hepatitis B & $07(3.2 \%)$ \\
Idiopathic & $34(15.5 \%)$ \\
HCC and Cirrhosis & $05(2.3 \%)$ \\
Autoimmune hepatitis & $04(1.8 \%)$ \\
Budd-Chiari Syndrome & $03(1.4 \%)$ \\
Others & $32(14.4 \%)$ \\
Total & $220(100.0 \%)$ \\
\hline
\end{tabular}

$\mathrm{HCC}=$ hepatocellular carcinoma

band ligation technique was applied in $39.1 \%$. The ethanolamine oleate was the most used sclerotic substance, and in $57.6 \%$ of the cases only one session was enough to stop the bleeding that had variceal origin.

Only nineteen patients $(0.6 \%)$ were submitted to a surgical treatment during the acute episode of bleeding. In these cases, the procedure of esophagogastric devascularization associated with splenectomy (EGDS) was carried out in $63.2 \%$ of the patients. The control of bleeding was successful in $78.9 \%$ of the cases.

In the admission period $2.3 \%$ of the patients died, and this index went up to $14.6 \%$ after hospital internment.

In the one-year follow-up period only two patients $(1.1 \%)$ were submitted to a liver transplantation. In this period, $20.7 \%$ of those who were classified as Child class $\mathrm{B}$ at admission changed to Child class A. Survival rate after one-year was higher for Child class A (Figure 1).

\section{Discussion}

Gastroesophageal varices are the most common cause of bleeding and one of the main causes of death among patients admitted with a diagnosis of portal hypertension. These varices are also the most severe complication of portal hypertension that may occur in cirrhotic patients $[1,7,20]$. This medical condition, with upper gastrointestinal bleeding caused by gastroesophageal varices, indicates in most cases a substantial hematemesis that can be followed by melena or hematochezia. It was discovered that only $14.5 \%$ of the analyzed patients were suffering from serious bleeding. Apart from this, there was a tendency of association between the admission data and the

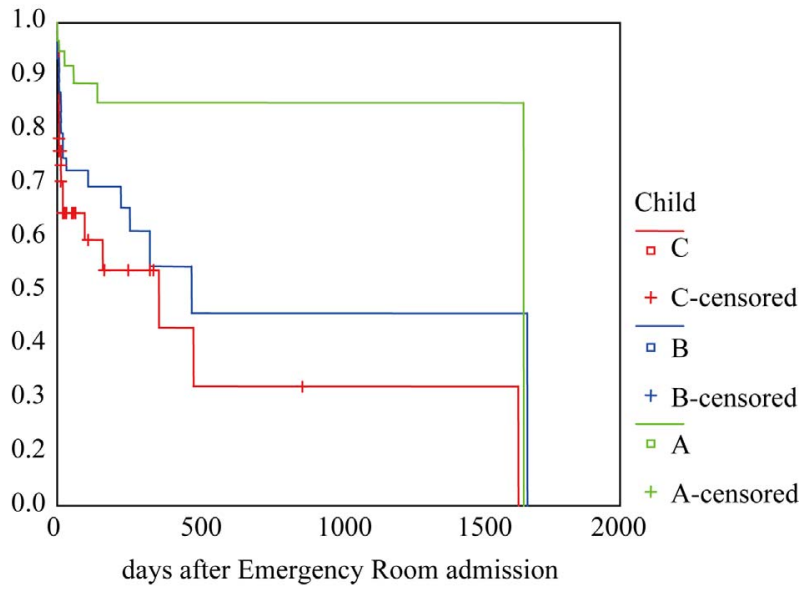

Figure 1. Comparison of patient survival rate between Child $A$ and Child B and Child C. Patient survival in the Child A was significantly better than in the Child B or $C(p<0.001)$

patients' evolution. Thus, a higher number of deaths occurred among those patients admitted with a diagnosis of hematemesis or hematemesis and melena (20 and $29.1 \%$, respectively) in comparison to those that were admitted with a diagnosis of only melena $(10.8 \%)$. This result is probably a result of the poor medical condition.

Gastroesophageal varices are a consequence of portal hypertension, which, in most of the severe cases, are associated with complications such as ascites, liver encephalopathy, flapping, liver failure and even death due to hemorrhagic shock $[12,28,31]$. During the admission period to the Emergence Room of Clinical HospitalUNICAMP, a large number of the patients showed ascites $(48.2 \%)$, although other factors to indicate the level of seriousness of portal hypertension were not found.

The degree of liver encephalopathy is expressed by neuropsychological alterations that have a metabolic origin and are potentially reversible, reflecting the functional aggravation of the liver. In this study $30.8 \%$ of admitted patients had degree I, with an equivalent proportion of patients with degree II.

The classification of Child-Turcotte, modified by Pugh, defines three distinct groups (A, B or C) that represent the degree of liver failure. This classification shows an important prognostic value in terms of mortality of these patients $[14,16,22]$. Most of them were classified as Child class B at admission (40\%). However, during one year a significant change was observed in the classification of Child-Turcotte-Pugh in consequence of the applied treatment. After this period, $20.7 \%$ of those who were classified as Child class B at admission stayed in Child class A, while $39.3 \%$ of those classified as Child class $\mathrm{C}$ at admission changed to Child class B. According to the Child-Turcotte-Pugh classification, survival rate after one-year was higher for Child class $\mathrm{A},(85 \%)$, 
followed by Child class B (55\%) and Child class C $(47 \%)$. These data show the necessity of classification of patients according to Child-Pugh due to its great prognostic value.

A variceal hemorrhage, in general, occurs without obvious precipitating factors and without pain. In the admission period $2.3 \%$ of the patients died, and this index went up to $14.6 \%$ after hospital internment, similar to the results mentioned in the literature $[11,12,14,21,27,28]$.

The endoscopic diagnosis is carried out by observing the right place of the bleeding or viewing varices that have a considerable size varying from moderate to big in those cases where there is no other lesion that could justify the bleeding $[1,6]$. Early upper gastrointestinal endoscopy (in the first 24 hours after the beginning of bleeding) has been recommended because it allows the application of the adequate therapeutic treatment [14]. Two hundred and thirteen patients $(96.8 \%)$ were submitted to upper gastrointestinal endoscopy in the first 24 hours after admission to the hospital. According to Osaka's classification (1979), there were $F 3$ varices in $38.0 \%$ of the patients, $C B$ varices in $25.1 \%$ and $R C S$ varices in $12.6 \%$. The highest percentage $(41.5 \%)$ was situated in the distal esophagus.

Pharmacological treatment in acute bleeding is based on the use of vasoconstrictors (vasopressin or somatostatin and similar, $\beta$-adrenergic blockers) and nitrovasodilators $[5,10,13,14]$. Most of those patients 51 $(45.9 \%)$ were submitted to a treatment with octreotide, a substance that is similar to somatostatin, with a dose of $0,05 \mathrm{mg}$ IV and maintenance of $1 \mathrm{mg}$ a day during an average period of four days, succeeding in $74.2 \%$ of the cases.

The tamponade of gastroesophageal varices is indicated only in cases of acute bleeding or when the use of vasoconstrictors, sclerotherapy and embolization does not obtain any success. The success of the method varies between 44 to $90 \%$ of the cases $[14,15,18,23]$. The tamponade with a Sengstaken-Blakemore tube was used in $30.5 \%$ of the patients admitted with a diagnosis of upper gastrointestinal bleeding by gastroesophageal varices, used during a period of 24 hours in $49.2 \%$ of the cases. This treatment had succeeded in controlling bleeding in $49.3 \%$ of the cases, confirming the data contained in the literature referred to $[14,15,18,23]$.

Endoscopic intervention (with sclerosis or ligature of varices) could be used as an optional treatment against acute variceal bleeding. A considerable control of the bleeding was reached in cases submitted to this treatment varying from 75 to $90 \%$ [2]. Many substances with sclerotic properties can be used. However, if the bleeding persists after the initial sclerotherapy, a second session should be used in a period of 24 hours; if it still persists, another therapeutic treatment has to be used. During the treatment process, new sessions might be carried out with a view to eradicating the varices and, at the same time, preventing new bleeding $[3,8,9,14,15,29-32]$. Endoscopic intervention was used in $41.8 \%$ of the patients, the elastic band ligation technique was applied to $39.1 \%$ of them and sclerotherapy to the others $(60.1 \%)$. The ethanolamine oleate was the most used sclerotic substance, and in $57.6 \%$ of the cases only one session was enough to stop the bleeding that had a variceal origin. During a one-year period, the number of necessary sessions to eradicate the varices varied from three to nine sessions in some cases.

Emergency surgery is usually carried out for only 15 to $25 \%$ of the patients that keep on bleeding in spite of treatment with non-surgical therapy $[4,13,15]$. Some Brazilian authors have demonstrated that it is possible to use the distal splenorenal shunt in the emergency period because of the satisfactory results obtained [19, 24]. Only nineteen patients $(8.6 \%)$ were submitted to a surgical treatment during the acute episode of bleeding. In this situation the process of esophagogastric devascularization associated with splenectomy (EGDS) was applied to $63.2 \%$ of the patients. There was a successful control of bleeding in $78.9 \%$ of the cases. In the first following year, $5.2 \%$ of the other patients were submitted to surgical treatment after new episodes of upper gastrointestinal bleeding caused by gastroesophageal varices.

A liver transplant is the only procedure that has a great potential to control the bleeding, to correct the portal hypertension and to restore the normal liver function. It is an option for those patients with an advanced liver disease with possible variceal bleeding complications $[16,17,24,25]$. However, a great percentage of patients with bleeding caused by varices cannot be submitted to a transplant due to factors such as advanced age, drug abuse, non-compliance, active alcoholism or advanced diseases in other organs and long time in waiting list because of the shortage of donor organs $[4,16,26]$. In this work only two patients $(1.1 \%)$ were submitted to a liver transplant during a one-year period. Recent reports showed that portal blood flow-preserving procedures performed by a highly skilled surgical team in a wellselected patient population offer excellent results, with very low operative mortality rate $(1 \%)$, very good 5 -year survival, low encephalopathy rate and a low rebleeding rate. No other option can offer such promising results. Therefore, these portal blood flow-preserving procedures have an important role for patients waiting for a liver transplantation $[4,16]$.

In conclusion, the incidence of upper digestive hemorrhage caused by acute variceal bleeding was $28.6 \%$ in our Emergency Room with low mortality rate. It is im- 
portant to consider that the gastroesophageal varices are still a significant cause of upper gastrointestinal bleeding and may lead to death. Significant prognostic factors were liver failure score, according to Child-Pugh-Turcotte's classification and the efficiency of the applied treatments. We conclude that portal hypertension treatment should be considered again.

\section{References}

[1] N. A. Andreollo, E. R. Rodas, M. C. Y. B. Braile, M. N. J. Faria, A. Yamanaka and N. A. Brandalise, "Diagnóstico Endoscópico da Hemorragia Digestiva Alta: Estudo Retrospectivo em Hospital Universitário," Arq Bras Med, Vol. 63, No. 1, 1989, pp. 43-47.

[2] M. S. Barsoum, F. I. Bolous and A. A. El-Rooby, "Tamponade and Injection Sclerotherapy in the Management of Bleeding Oesophageal Varices," British Journal of Surgery, Vol. 69, No.2, 1982, pp. 76-78. doi:10.1002/bjs.1800690206

[3] L. S. Leonardi, I. F. S. F. Boin, N. A. Brandalise, N. A. Andreollo, F. Callejas Neto and J. C. Pareja, "Results of the Azigo-Portal Disconnection and Splenectomy Associated with Sclerotherapy in Schistosomiasis," $A B C D$ : Arquivos Brasileiros de Cirurgia Digestiva, Vol. 3, No. 4, 1988, pp. 99-103.

[4] I. F. S. F. Boin, G. Sevá-Pereira, D. Bittencourt and L.S. Leonardi, "Results of Surgical Treatment of Portal Hypertension," In: E. M. Gonzalez and M. H. Paschoal, Eds., $3^{\text {rd }}$ World Congress Of IHPBA, Book Proceedings, Madri, 1999. pp. 94-96.

[5] J. Bosch, G. D’amico, A. Luca, J. C. García-Pagán, F. Feu and A. Escorsell, "Drug Therapy for Variceal Haemorrhage," In: J. Bosch et al., Eds., Portal Hypertension Pathophysiology and Treatment, Blackwell Scientific Publications, London, 1994. pp. 108-123.

[6] P. Dave, J. Romeu and J. Messer, "Upper Gastrointestinal Bleeding in Patients with Portal Hypertension: A Reappraisal," Journal of Clinical Gastrenterology, Vol.78, No. 11, 1983, pp. 113-115. doi:10.1097/00004836-198304000-00004

[7] O. Duhamel, J. P. Carle, J. P. Daures, A. Boyer, J. Gislon, B. Nalet, et al. "Primary Prevention of Digestive Hemorrhage, Caused by Rupture of Esophageal Varices, by Endoscopic Sclerotherapy in Patients with Liver Cirrhosis. Multicenter Randomizes Controlled Study," Gastroenterol Clin Biol, Vol. 18, No. 1, 1994, pp. 57-62.

[8] M. A. Fallah, C. Praskash and S. Edmundowicz, "Acute Gastrointestinal Bleeding," Gastroenterology Clinics of North America, Vol. 84, No. 5, 2000, pp. 1183-1208.

[9] J. S. Goff, "Gastroesophageal Varices: Pathogenesis and Therapy of Acute Bleeding," Gastroenterology Clinics of North America, Vol. 22, No. 4, pp. 779-800.

[10] N. D. Grace, "A Hepatologists View of Variceal Bleeding," The American Journal of Surgery, Vol. 160, No. 1. 1990, pp. 26-31.
doi:10.1016/S0002-9610(05)80864-5

[11] D. Y. Graham and J. L. Smith, "The Course of Patients after Variceal Hemorrhage," Gastroenterology, Vol. 80, No. 4, 1981, pp. 800-809.

[12] R. J. Groszmann, J. Bosch, N. D. Grace, H. O. Conn, G. Garcia-Tsao, M. Navasa et al. "Hemodynamic Events in a Prospective Randomized Trial of Propranolol Versus Placebo in the Prevention of a First Variceal Hemorrhage," Gastroenterology, Vol. 99, No. 5, 1990, pp. 1401-1407.

[13] V. A. Luketic and A. J. Sanyal, "Esophageal varices i. Clinical Presentation, Medical Therapy, and Endoscopic Therapy," Gastroenterology Clinics of North America, Vol. 29, No. 2, 2000, pp. 337-385. doi:10.1016/S0889-8553(05)70119-9

[14] D. S. Matloff, "Treatment of Acute Variceal Bleeding," Gastroenterology Clinics of North America, Vol. 21, No. 1, 1992, pp. 103- 118.

[15] M. A. Mercado, H. Orozco, F. F. Ramírez-Cisneros, C. A. Hinojosa, J. J. Plata and J. Alvarez-Tostado, "Diminished Morbidity and Mortality in Portal Hypertension Surgery: Relocation in the Therapeutic Armamentarium," Journal of Gastrointestinal Surgery, Vol. 5, No. 5, 2001, pp. 499-502. doi:10.1016/S1091-255X(01)80087-1

[16] M. J. Orloff, M. S. Orloff, B. Girard and S. L. Orloff, "When is Liver Transplant Indicated in Cirrhosis with Bleeding Varices?" Transplantation Proceedings, Vol. 33, No. 1-2, 2001, p. 1366. doi:10.1016/S0041-1345(00)02512-4

[17] L. Pagliaro, G. D'amico, L. Pasta, F. Politi, G. Vizzini, M. Traina, et al. "Portal Hipertension in Cirrhosis: Natural History,” In: J. Bosch, R. J. Groszmann, Eds., Portal Hypertension Pathophysiology and Treatment, Blackwell Scientific Publications, London, 1994, pp. 72-92.

[18] J. Panes, J. Teres and J. Bosch, "Efficacy of Balloon Tamponade in Treatment of Bleeding Gastric and Esophageal Varices: Results in 151 Consecutive Episodes," Digestive Diseases and Sciences, Vo. 33, No. 4, 1988, pp. 454-459. doi:10.1007/BF01536031

[19] J. C. Pareja and L. S. Leonardi, "Hemorragia digestiva alta por varizes esofagogástricas,” In: L. S. Leonardi, Ed., Cirurgia de Urgência Do Aparelho Digestivo, Medsi, Rio de Janeiro, 1986, pp. 111-117.

[20] H. C. Pinto, A. Abrantes and A. V. Esteves, "Long Term Prognosis of the Liver and Upper Gastrintestinal Bleeding," The American Journal of Gastrenterology, Vol. 84, No. 10, 1989, pp. 1239-1243.

[21] D. Prandi, B. Rueff, J. Roche-Sicot, "Life-Threatening Hemorrhage of the Digestive Tract in Cirrhotic Patients," The American Journal of Surgery, 1976, Vol. 131, No. 2, 204-209. doi:10.1016/0002-9610(76)90098-2

[22] R. N. H. Pugh, I. M. Murray-Lyon and J. L. Dawson, "Transection of the Oesophagus for Bleeding Oesophageal Varices," British Journal of Surgery, Vol. 60, No. 8, 1973, pp. 646-649. doi:10.1002/bjs. 1800600817

[23] S. Raia, L. C. Silva, L. C. C. Gayotto, S. C. Foster, J. Fukushima and E. Strauss, "Portal Hypertensionin Schis- 
tosomiasis. A Long Term Follow-up of a Randomized Trial Comparing Three Types of Surgery," Hepatology, Vol. 20, No. 2, 1994, pp. 398-403. doi:10.1002/hep. 1840200220

[24] L.F. Rikkers. Bleeding esophageal varices. Clin Cir Am Norte Vol. 67, No. 3, 1987, pp. 487-488.

[25] L. F. Rikkers, "Definitive Therapy for Variceal Bleeding: A Personal View," The American Journal of Surgery, Vol. 160 , No. 1, 1990, pp. 80-85. doi:10.1016/S0002-9610(05)80873-6

[26] D. L. Jacobs and L. F. Rikkers, "Indications and Results of Shunt Operations in the Treatment of Patients with Recurrent Variceal Hemorrhage," Hepatogastroenterology, Vol. 37, No. 6, 1990, pp. 571-574.

[27] L. F. Rikkers and G. Jin, "Variceal Hemorrhage: Surgical Therapy," Gastroenterology Clinics of North America, Vol. 22, No. 4, 1993, pp. 821-842.

[28] H. Yoshida, Y. Mamada, N. Taniai, S. Mineta, Y. Kawano,
Y. Mizuguchi, et al. "Shunting and Nonshunting Procedures for the Treatment of Esophageal Varices in Patients with Idiopathic Portal Hypertension," Hepatogastroenterology, Vol. 57, No. 102-103, 2010, pp. 1279-1284.

[29] J. L. Smith, D. Y. Graham, "Variceal Hemorrhage: A Critical Evaluation of Survival Analysis," Gastroenterology, Vol. 82, No. 5 Pt 1, 1982, pp. 968-973.

[30] W. Andraus, R. Pinheiro, L. B. Haddad, P. Herman and L. A. D'Albuquerque, "The Best Approach for Splenectomy in Portal Hypertension," Surgery, 2011. [Epub ahead of print].

[31] E. Strauss, "Band ligation, sclerotherapy, both or... brains?" The American Journal of Gastroenterology, Vol. 92, No. 6, 1997, pp. 920-923.

[32] L. Li, C. Yu and Y. Li, "Endoscopic Band Ligation Versus Pharmacological Therapy for Variceal Bleeding in Cirrhosis: A Meta-Analysis," The Canadian Journal of Gastroenterology, Vol 25, No. 3, 2011, pp. 147-155. 